\title{
Basic Experience of Vocational Education Reform in Singapore and the
}

\section{Enlightenment}

\author{
Cao Shizhu ${ }^{1}$, Huang Naizhu ${ }^{1}$, a, ${ }^{*}$, Zhong Jiaming ${ }^{1}$, He Ling $^{1}$ \\ ${ }^{1}$ XiangNan University, Chenzhou, Hunan, China \\ a huangnzh@163.com \\ *Corresponding author
}

\begin{abstract}
Singapore vocational education has made outstanding contributions to the economic and social development in Singapore. Such vocational education advocates the educational ideas of "student-centered teaching", "value orientation", "less teaching and more learning" and "teaching factory". Furthermore, it has trained countless excellent applied talents for economic and social development in Singapore based on the educational version of "Meditation for schools and citizens". Therefore, local colleges and universities in China should actively learn from the successful experience of Singapore vocational education reform during the transformational development. Then, the educational ideas will serve the local economic and social development better, thus with better cooperation with school-enterprises. Besides, more applied talents will be trained with strong employment and pioneering ability.
\end{abstract}

Keywords: Vocational education; Education reform; Local colleges and universities; Transformational development

\section{新加坡职业教育改革的基本经验及其启示 \\ 曹石珠 ${ }^{1}$, 黄乃祝 ${ }^{1, a, *}$, 钟嘉鸣 ${ }^{1}$, 何玲 ${ }^{1}$ \\ ${ }^{1}$ 湘南学院, 椰州, 湖南, 中国 \\ ahuangnzh@163.com \\ 通讯作者}

\begin{abstract}
摘要. 新加坡职业教育为新加坡的经济社会发展作出了卓越贡献。新加坡职业教育本着 “重思 考的学校，好思考的国民” 的教育愿景，提倡 “以学生为中心”、“价值导向”、“少教多学”、 “教学工厂”的教育理念, 为新加坡经济社会发展培养了大量卓越的应用型技能人才。当前, 我国地方高校在转型发展中应主动借鉴新加坡职业教育改革成功经验, 把办学思路真正转到 服务地方经济社会发展上来，转到产教融合校企合作上来，转到培养应用型技术技能型人才 上来, 转到增强学生就业创业能力上来。
\end{abstract}




\section{关键词: 职业教育; 教育改革; 地方高校; 转型发展}

\section{一、引言}

有着 “花园城市” 美誉之称的新加坡位 于马来半岛南端, 地处东南亚交汇处, 扼太 平洋与印度洋的航运咽喉要到——马六甲海 峡, 是亚、澳、欧、非的海上交通枢纽。新 加坡自 1965 年脱离马来西亚联邦以来, 对外 实行全方位开放的政策, 对内根据经济发展 需要, 紧抓人才规划和人力资源开发, 把教 育作为构建国家与民族综合实力的重要支 柱, 大力改革和发展教育, 在短短三十多年 中从一个资源贵乏、低生育率、收入差距不 断拉大、种族矛盾丛生的积贫积弱渔村一跃 发展成为政治稳定、经济发达的新兴工业化 国家, “如凤凰从灰烬中再生一样” 崛起于东 南亚, 跻身 “亚洲四小龙”之首。新加坡积 极推行兼容并蓄、东西融合和开放包容的精 英治国理念, 极力打造 “重思考的学校, 好 学习的国家” 形象, 大力提倡国民危机意识、 责任意识、诚信意识和团队意识培养, 使国 家竞争力、社会和谐度、人均收入等主要指 标达亚洲乃至世界前列, 到处呈现 “自律、 自强、乐观、向上” 的国民形象和美丽、开 放、充满活力的国家气象。

\section{二、新加坡教育改革基本理念}

新加坡的经济社会发展成就很大程度上 得益于行之有效的教育制度尤其是职业教育 制度。新加坡的国家发展战略中提出 “重思 考的学校, 好思考的国民” 教育愿景; 提倡 “育人为本” 和 “因材施教、发挥所长, 培 养团队精神, 鼓励学生勇于开拓、勇于尝试、 不怕失败, 培养创新、创业精神” 的教育理 念; 推行德智体群美全方位教育模式; 强调 学生全面发展, 成为能思考及有责任感的好 公民, 学校使命就是为年轻人提供各种各样 的机会, 让他们在技能、品格及价值观上得 到全面发展, 以确保他们能够继续表现出色, 带领新加坡向前迈进; 学校引导学生树立务 实化的核心价值观: 对个人行为负责、有效 交流自己想法、做有责任感的领导人、提出 有创造性解决方案, 最终培养出自信、从容、 谦虚、诚信的学生。

\section{三、新加坡职业教育改革基本观点}

新加坡职业教育改革是在坚持教育改革
基本理念前提下, 在深入学习、研究和借鉴 德、英等国家职业教育特色基础上构建了自 己独特的职业教育制度, 为国家经济腾飞和 可持续发展奠定了坚实的人才基础。研究和 学习新加坡职业教育改革的成功经验, 对于 处在转型发展中的我国地方高校来说具有十 分重要的启发意义和借鉴价值。

\section{(一) “以学生为中心”}

“以学生为中心” 是新加坡职业教育走 向成功的一个重要教育教学理念, 南洋理工 大学原校长徐冠林教授接待国外来访学者曾 说的“我们没有什么特别好的学生管理制度, 学生有什么样的需求, 学校就提供什么样的 服务; 教师的以身作则, 行为世范就是最好 的管理” 就是其生动写照。“ “以学生为中心” 是 20 世纪美国进步主义教育运动提出的一 个崭新话题” ${ }^{[1]}$ ，是对传统的 “以教师为中 心” 教育理念的颠覆, 是职业教育主动适应 信息时代青年学生学习环境和学习方式变化 的重要理念。新加坡 “以学生为中心” 的教 育教学理念集中体现在课程开设、教学实施、 教学条件、学生生活学习环境等各个方面, 主要包括：第一，学生是学习的主体，教学 中教师要尊重学生、信赖学生, 与学生建立 平等关系, 让学生在学习活动中享受更多的 成功。第二, 教学活动是教师设计、学生参 与的全方位活动, 学生成为教学过程的主体, 教师成为教学过程的导师, 引导学生开展各 种有声有色的教学活动, “教师逐渐由 '演员” 升格为 “导演”, 学生由 “观众 (或/听众)' 逐渐升格为 “演员”, 师生一起对 “剧本” (教 学内容) 进行再创作” ${ }^{[2]}$, 学生在教学中不仅 学到了知识、技能, 在团队精神、主体精神 和创新精神上也得到了培养和锻炼。第三, 学生生活设施的设计、建设与管理上尽量做 到舒适、美观和人性化, 如宿舍风格各异且 时尚美观, 周边绿化让人感觉心旷神怡, 周 边配备独具特色餐厅方便就餐; 校内道路设 施斑马线, 所有车辆遇斑马线一律停车让学 生先行; 校内游泳馆、室内运动场和健身房、 室外足球场和篮球场等运动设施一律免费开 放, 主要运动场所晚上 9 点前灯光全部打开; 校内设置多条免费巴士线路供学生乘车上 
课、自修、就餐、回宿舍等; 主要教学楼、 图书馆、餐厅与宿舍、巴士站之间设置防日 酙雨淋的人行道, 方便学生出行。

\section{（二）“价值导向”}

新加坡的职业教育导向一直随着时代要 求不断变革, 自1959年的生存导向, 到1979 年的效率导向, 再到1997年的能力导向。2011 年9月, 教育部部长王瑞杰在新加坡教育部工 作蓝图大会上指出: “新加坡未来的教育方向 将由 “能力导向” 转向 “价值导向”, 即通 过教育改革让教育系统变得更加以学生为中 心, 更加关注学生全面教育, 更加强调价值 观和品格发展, 这种 “学生中心、价值观导 向的教育” 既要给予学生自信心和自我意识, 培养他们坚忍不拔的意志力, 即培养学生的 “自我价值”; 又要培养学生在多元种族、多 元文化的社会, 尊重、负责、关怀和赏识他 人, 即培养学生的 “道义价值”; 还要培养学 生成为坚强、有毅力、有知识、有见闻, 国 家有难, 能奋起捍卫祖国的好公民, 即培养 学生的 “公民职责价值”。

\section{（三）“少教多学”}

2004 年新加坡总理李显龙在国庆贺词中 就教育问题指出 “我们少教一点, 学生就能 多学一点”。从此, “少教多学” 成为新加坡 各级各类学校办学的基本理念。其实, “少教 多学” 并不是一个新理念, 早在十七世纪捷 克教育家夸美纽斯《大教学论》里就有过精 辟论述: “找出一种教育方法, 使教师因此可 以少教, 使学生多学; 使学校因此可以少些 喧器、厌恶和无益的劳苦, 独具闲暇、快乐 及坚实的进步”。职业技术教育由于其培养目 标为应用技能人才, 人才培养模式强调以应 用为主旨, 理论够用为度, 为了突出学生职 业技能培养, 教育教学改革急需提倡 “少教 多学”, 即设计以学生好学为中心的教育体 系, 大力削减课程讲授内容, 根据行 (企) 业需求创建独有特色的实践教学体系, 实现 定向于行业、定性于专业、定型于应用、定 位于教学、定格于实践的专业应用型教育, 努力增强学生的实践、创新与可持续发展能 力。

\section{(四) “教学工厂”}

新加坡职业教育公认标志就是独具一格 的 “教学工厂” 教育理念, “教学工厂” 是新
加坡在学习和借鉴德国 “双元制” 教学模式 基础上结合本国国情所创造的一种教育模 式, 其实质是将实际的企业工作环境引入教 学中, 让学生在参与工作项目的过程中做到 “教学做合一”, 实现教学与实践的无缝对 接。“教学工厂”教育理念的特点有: 一是将 实习教学由传统的模拟到模仿再到融合; 二 是在教学环境内营造企业实践环境, 并将两 者紧密融合; 三是以学院为本位, 在现有教 学系统基础上设立, 而不是以企业为本位。 举个例子来说, 当某个企业在生产或技术上 遇到问题时, 就与学校签订协议交予学校解 决该问题并支付一定费用, 学校组织相关专 业教师团队带领学生在实验（训）室攻关, 这样学校实验（训）室就相当于工厂的车间, 而专业教师和学生就相当于员工。“教学工 厂”教育理念既能为学生提供一个更完善和 有效的学习环境和过程; 又能确保课程教学 与企业需求挂钩, 理论教学与实践教学有机 结合, 达到培养学生的实践能力、创新能力 和解决实际问题能力; 还能实现教师专业培 训和能力成长, 促进校企政之间联系, 使学 校对企业和政府产生强大的吸引力。

\section{四、新加坡职业教育改革对我国地方高校转 型发展的启示}

20 世纪 90 年代后期, 随着我国高等教 育大众化, 一些办学历史悠久、实力较强的 高职高专院校, 经调整、合并升格为地方本 科高校。这些地方高校在办学过程中基本沿 袭传统学术性高校办学模式, 导致所培养人 才与地方经济社会发展需求严重脱节, 出现 大学生 “就业难” 与企业 “用工荒” 的结构 性矛盾。目前, “欧洲发达国家应用技术型人 才与学术型人才培养的比例一般在 $8: 2$, 这 与社会经济发展对人才需求的结构相吻合” [3]。《国务院关于加快发展现代职业教育的 决定》提出: “采取试点推动、示范引领等 方式, 引导一批普通本科高等学校向应用技 术类型高等学校转型, 重点举办本科职业教 育”，随后，教育部颁发《关于开展引导部 分本科高校向应用技术高校转型发展改革试 点的指导意见》（征求意见稿），地方高校 应借此机遇在国家政策指引下走出办学定位 攀高、趋同误区, 根据自身办学历史和办学 实力, 举办应用技术大学, 办出特色和水平。 


\section{（一）地方高校转型发展要正确理解 “就业 导向” 教育}

袁贵仁部长在 2015 年初的全国教育工 作会议上指出: “地方本科高校转型要把办 学思路真正转到服务地方经济社会发展上 来, 转到产教融合校企合作上来, 转到培养 应用型技术技能型人才上来, 转到增强学生 就业创业能力上来”。一些地方高校却在转 型发展中片面理解袁部长的四转精神, 把职 业教育办成了就业教育, 错误地理解 “就业 导向” 教育。其实, “就业导向” 教育就是 要求地方高校立足于 “地方性、应用型” 办 学定位, 围绕区域经济社会发展需主动调整 学科专业结构、师资素质水平和人才培养模 式, 从 “围绕学校资源办学” 到 “围绕学生 办学” 转变, 并始终坚持把 “学科专业设置 与地方经济发展的契合度, 办学质量与效益 对地方经济社会发展的支撑度, 人民对办学 质量与水平的满意度” 作为衡量学校办学成 败的重要标准。可现实情况是有的地方高校 为了追求所谓的高就业率, 畸形发展专业技 能教育, 却严重忽视以职业素养为重点的全 面素质教育, 结果是学生的专业技能水平 (以 技能等级证为标志) 提高了, 可爱岗敬业、 诚信友善、团结合作等职业素养并没有提高, 从长远来看无法真正培养出满足地方经济社 会发展需要的高素质应用型技能人才。

目前我国面临的国际国内形势要求地方 高校转型发展必须以学生为中心, 关注学生 的全面教育和价值观、品格形成。职业教育 要从 “就业导向” 转向 “价值观导向”, 既 要重视学生专业技能教育, 也要重视学生文 化素养、职业道德、身心健康、就业创业教 育, 将学生的 “自我价值、道义价值、公民 职责价值” 统筹培养, 使学生成为践行社会 主义核心价值观 “富强、民主、文明、和谐, 自由、平等、公正、法制, 爱国、敬业、诚 信、友善” 表率和富有事业心和责任心、具 备必要的文化知识、良好的职业道德、熟练 的专业技能、健康的身心素质和一定就业创 业能力的高素质应用型人才。

\section{(二) 地方高校转型发展要坚持 “校企合作、 工学结合” 办学模式}

所谓 “校企合作、工学结合” 办学模式 就是 “将学校与企业两种风格迥异的教育环
境和教育资源进行整合，按照企业发展对人 才知识、能力和素质结构的要求, 共同培养 适应企业建设和发展的高素质应用型技能人 才, 实现学校与企业的优势互补和双赢发展” ${ }^{[4]}$, 这种办学模式以职业为导向, 以市场需 求为运作平台, 既能提高学生的综合素质和 就业竞争能力, 又能提高学校教育对社会需 求的适应能力。《国家中长期教育改革和发 展规划纲要（2010一2020）》指出: “把提 高质量作为重点; 以服务为宗旨, 以就业为 导向, 推进教育教学改革; 实行工学结合、 校企合作、顶岗实习的人才培养模式”。地 方高校转型发展要借鉴新加坡 “教学工厂” 的教育理念, 按照 “校企合作、工学结合” 办学理念实施教学做一体化人才培养模式改 革, 主动加强与区域行 (企) 业的联系, 大 力加强校企联合实验室、实习（训）基地、 大学生创新教育实践中心建设, 为学生创造 模拟仿真的训练环境, 让学生在做中学、学 中练, 使学生的专业技能得到扎实培养, 分 析问题、解决问题和灵活应变的创新能力得 到提高。

\section{（三）地方高校转型发展要始终坚持 “向教 学管理要质量” 的管理理念}

地方高校转型发展要牢固确立人才培养 的中心地位, 树立科学的高等教育发展观, 坚持稳定规模、优化结构、强化特色、注重 创新, 走以质量提升为核心的内涵式发展道 路。《国家中长期教育改革和发展规划纲要

（2010-2020 年）》指出： “提高质量是高 等教育发展的核心任务, 是建设高等教育强 国的基本要求”。地方高校作为一所培养高 层次应用型人才的大学, 应坚持 “以提高质 量为核心” 的增长模型, 遵循高等教育规律, 树立科学的质量发展观, 围绕应用型人才培 养, 进一步坚持各项工作、各项改革的质量 导向, 完善有利于质量提升的体制机制, 以 教学为中心, 加大教学基础设施建设, 实施 人才强校工程, 引导教师潜心育人, 不断深 化教学改革, 有效提升应用型人才培养质量。

地方高校转型发展 “向教学管理要质量” 主要体现在: 第一, 对学生的教学管理要“严” 字当头: 教学 (包括理论教学与实践教学) 是提高教育质量, 推动高等教育内涵发展的 主战场。当前, 地方高校对学生的教学管理 
都是 “严进宽出”, 经过激烈高考竞争后进入 大学的学子们仿佛张开自由的翅膀, 学习压 力和动力普遍消失, 上课迟到、心不在焉、 睡觉、逃课司空见惯。地方高校教学管理严 字当头就是给大学生增加压力, 用压力激发 大学生向上的动力, 如浙江省教育厅 2014 年 5 月颁发的《关于切实加强高等学校学生学 业指导和管理的意见》指出: “经考核评价未 达到培养合格标准的学生, 须重修课程或延 期毕业; 严格考试管理, 建立试卷事后评审 和抽查制度, 实行试卷密封匿名改卷; 学校 不得安排任何形式的毕业前清理性考试; 严 肃处理考试作弊和论文抄袭行为, 建立考试 和毕业论文抽查制度; 建立健全学业预警和 退学制度, 对无法达到专业毕业要求的学生, 须按规定给予留级、转学、退学处理” ${ }^{[5]}$; 第二, 对教师的教学管理要科学规范: 当前, 地方高校教师由于受到功利主义人生哲学影 响, 浮躁、肤浅、追逐名利成为普遍现象, 教师的教学责任感下降、教学方法陈旧和单 调, 在教学质量面前, 地方高校教师普遍出 现教师专业化困境、教学与科研两难困境、 因材施教困境。为了解决地方高校教师教学 上的各种困境, 教学管理上除了大力加强教 师的世界观、人生观和职业道德教育外, 还 需创造条件大力加强学校 “双师型” 教师队 伍建设, 还需构建各种激励机制（竞争上课 机制、职称聘评分离机制、高职低聘或低职 高聘机制), 促进教师专业发展和教育教学方 法改革, 鼓励教师大胆采用项目导向、任务 驱动、情境体验、案例教学、模拟教学、探 究教学等方式开展教学工作, 培养国家经济 结构战略调整所需的适应生产、建设、管理、 服务一线的自立、自强、善于思考并能独立 解决问题的应用型高级技能人才; 第三, 构 建完全学分制的教学管理制度: 地方高校目 前的教学管理制度基于控制的思想, 师生的 主体性和教学自由度都不高。哲学家周国平 曾说: “现代的体制化教育对青少年的毒害是 很深的, 一切优秀学生都需要警惕体制化教 育带来的损害, 并认为一个学生的学习是否 卓有成效, 归根到底取决于他在体制化教育 面前为自己争得了多大的自主学习的自由” [6]。地方高校转型发展中构建完全学分制的 教学管理制度, 既能充分体现教学管理的人
性化和个性化, 又能解决大学生学习压力与 动力不足的问题。当然, 地方高校实行完全 学分制既需要构建合理的课程结构体系, 又 需要提供充足的课程教学资源、灵活的选课 制度, 还需要组织、指导学生尤其是新生选 课, 避免选课的盲目性和随意性。

\section{五、结束语}

新加坡职业教育改革为新加坡经济社会 发展作出了卓越贡献，使新加坡跻身 “亚洲 四小龙”之首。当前, 我国产业结构随着经 济社会发展需要进行调整, 高等教育结构随 着国家产业转型升级也应进行调整。地方高 校转型发展举办应用技术大学正是高等教育 结构调整的战略需要。当前，我国地方高校 在转型发展中应主动借鉴新加坡职业教育改 革成功经验, 把办学思路真正转到服务地方 经济社会发展上来, 转到产教融合校企合作 上来, 转到培养应用型技术技能型人才上来, 转到增强学生就业创业能力上来。

\section{致谢}

本研究得到湖南省普通高校教学改革研 究项目《应用型本科院校校企合作育人有效 性的研究》（湘教通 [2013]223 号）资助。

\section{References}

[1] Wen Jing, Main Ideas of American Progressive Education Movement and the Enlightenments $[\mathrm{J}]$. China Electric Power Education, 2008(15), 218-219

[2] Sun Zhiqiang, Further Implementation of "Student-Centered" Educational Idea in Classroom Teaching [EB/OL]

[3] Research Center of Transformational Development in Local Colleges, Application Technology University Alliance, Research Report of the Practice and Policy of Transformational Development in Local Universities, 2013, 13

[4] Chu Zhipeng, Thinking of the Cooperation between New Colleges and Enterprises Based on Demand Orientation [J]. The Guide of Science \& Education, 2011 (06), 24 
[5] Cai Jile, Zhu Zhenyue and Chen Zhiwei, Emphasis on the Quality of Higher Education in Zhejiang [N], 2015-5-21(05)

[6] Zhou Guoping, Zhou Guoping's Opinion on Education [M], East China Normal University Press, 2009, 254 